\title{
DEVELOPMENT AND APPLICATION OF H-JOINT STEEL PIPE SHEET PILES IN CONSTRUCTION OF FOUNDATIONS FOR STRUCTURES
}

\author{
Makoto Kimura ${ }^{\mathrm{i})}$, Shinya Inazumi ${ }^{\mathrm{ii}}$, Jonah Kiptanul Arap Too ${ }^{\mathrm{iii}}$, Koichi Isobe ${ }^{\mathrm{iv})}$, \\ YuUki Mitsuda $^{\text {v) }}$ and Yoshikazu NishiYama ${ }^{\mathrm{vi})}$
}

\begin{abstract}
This paper shows development and application potential of newly developed $\mathrm{H}$-joint steel pipe sheet piles (SPSPs) in SPSP structures. The authors have developed a new H-joint SPSPs technology from a simple idea in which two steel pipes are connected by $\mathrm{H}$-steel section welded on them in order to improve the performance and widen application areas of SPSP technology. The H-joint SPSP is expected to remediate problems of traditional joints in SPSPs. Installation accuracy, proposed field segment joint using a fillet welded splice plate and lateral bearing capacity for H-joint SPSPs were examined by field construction tests, full-scale bending tests and centrifuge model tests, respectively. Parametric studies using beam analysis were conducted to show that the cross sectional dimensions of SPSP foundations can be reduced by using $\mathrm{H}$-joint SPSPs and to estimate a joint efficiency $(\mu)$ for design of $\mathrm{H}$-joint SPSP foundation structures. The following observations were made from the studies: (1) H-joint SPSP can be installed with high driving accuracy due to rigidly welding 2 steel pipes and $\mathrm{H}$-steel in a factory, (2) The proposed field segment joint for $\mathrm{H}$-joint SPSP using a splice plate is strong and effective in bending, (3) H-joint SPSPs have high rigidity hence large lateral bearing capacity making them suitable in ensuring the stability of SPSP foundation structures, (4) A joint efficiency of H-joint SPSP foundation is larger than that of SPSP foundation with traditional joints, and (5) H-joint SPSP contributes to reducing the number of piles based on the reduction of the size dimension of the SPSP foundation.
\end{abstract}

Key words: beam analysis, centrifuge model test, field construction test, full-scale bending test, $\mathrm{H}$-joint steel pipe sheet pile, joint efficiency, lateral bearing capacity, steel pipe sheet pile foundation (IGC: E4/H1)

\section{INTRODUCTION}

Steel pipe sheet pile (SPSP) consists of a steel pipe and couplings welded on either side of the steel pipe. One SPSP is connected to the next one by interlocking their couplings and the interlocked couplings form a joint. The most commonly used joints in steel pipe sheet piles (SPSPs) are the P-P, P-T and L-T joints as shown in Fig. 1. These joints shall be referred to as "traditional joints" in this paper.

SPSPs were first used to construct a sheet pile wall in 1964 in Japan. It was then used as a foundation for a blast furnace in 1967 with the first SPSP bridge foundation being constructed across Ishikari River in Hokkaido in 1969. More than 1600 foundations have been constructed using SPSP to date. In recent years, application of SPSP in construction of vertical cutoff wall in coastal landfill sites has been reported. However, a number of

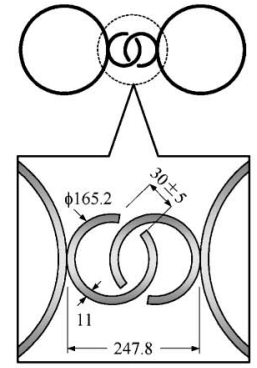

P-P joint

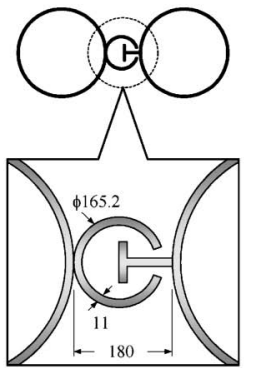

P-T joint

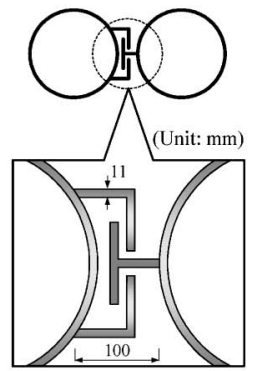

L-T joint
Fig. 1. Types and sizes of traditional joints in SPSP

problems related to the mechanical behavior and hydraulic characteristics of the traditional joints in SPSP need to be addressed. The problems associated with these traditional joints are as follows:

(1) Mortar and waterproofing chemical agents must be

i) Professor, International Innovation Center, Kyoto University, Japan.

ii) Research Associate, Graduate School of Engineering, Kyoto University, Japan. (inazumi@toshi.kuciv.kyoto-u.ac.jp).

iii) Lecturer, Department of Civil Engineering, Jomo Kenyatta University of Agriculture and Technology, Kenya.

iv) Formerly Graduate Student, Graduate School of Engineering, Kyoto University, Japan.

v) Formerly Graduate Student, ditto.

vi) Executive Director, Data-too Co. Ltd., Japan.

The manuscript for this paper was received for review on December 13, 2005; approved on November 17, 2006.

Written discussions on this paper should be submitted before November 1, 2007 to the Japanese Geotechnical Society, 4-38-2, Sengoku, Bunkyo-ku, Tokyo 112-0011, Japan. Upon request the closing date may be extended one month. 


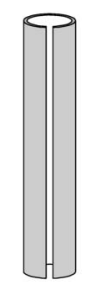

(a) Smooth internal surface

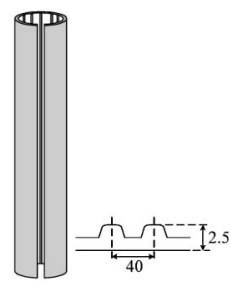

(b) Corrugated inner surface

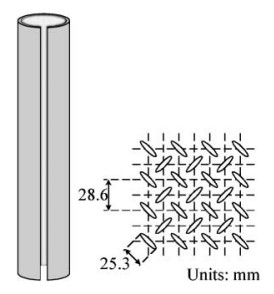

(c) Checkerred inner surface
Fig. 2. Corrugated and checkered inner surface of P-P joint pipe pile couplings

applied to seal and increase strength of the joints. These processes cause environmental degradation.

(2) In the current practice, mortar is injected into the joints after installation of SPSP is complete. However, the quality of grouting mortar is difficult to control. Uncertainty with regard to effectiveness of such treatment still remains.

(3) They have low construction accuracy hence excessive pile inclinations and rotations. Low construction accuracy results in a major cause of crushing of joints.

(4) They have low bending rigidity owing to vertical shear movements that occur at the joints when loaded.

(5) Only one pile is installed at a time causing unnecessary long construction periods and high operation costs.

Problems such as low construction accuracy, low rigidity and low waterproof performance are inherent with traditional joints. For over 40 years since SPSP were first used in Japan, however, significant developments and improvements on the traditional joints have not been performed. The few deliberate efforts have been the enlargement of steel pipe diameter in a bid to increase strength, and researching on how to increase water interception capacity of the joint sections. As a representative example for improving traditional joints, Katayama et al. (1993) proposed to increase the bonding strength between injected mortar and the inner surface of P-P joint by increasing the internal surface area of P-P joint by corrugating and checkering the inner surfaces of the joint pipes as shown in Fig. 2. The method, however, had not considered the quality of mortar grouting in the field and joint interlocking performance affected by low construction accuracy of traditional P-P joint. The old practice in which SPSPs are connected by interlocking the traditional joints and increasing the strength of joints by injecting mortar still remains the only SPSP technology. In order to overcome the problems which are inherent with traditional joint sections in SPSPs, it is necessary to reform the concept of joining each steel pipe together using traditional joints, and the shape of traditional joints. For the above reasons, the authors are introducing a new concept and method of inter-pile connection in SPSPs.

In this paper, a new joint in SPSP, referred to as $\mathrm{H}$-joint, is introduced to improve the performance and

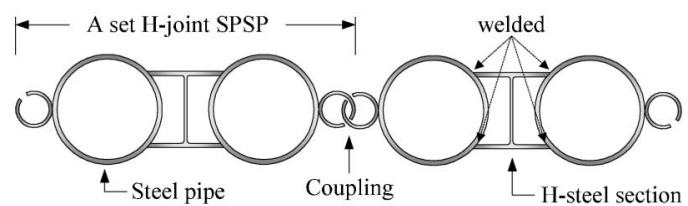

(a) Sectional view of $\mathrm{H}$-joint SPSPs

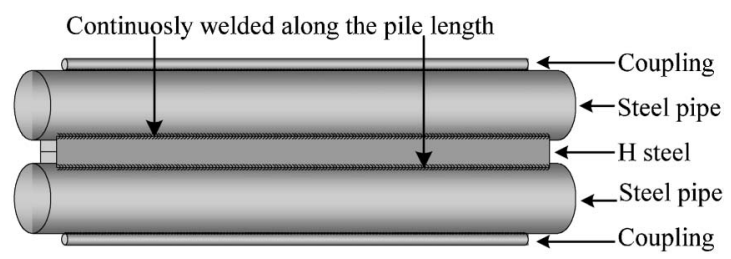

(b) H-joint SPSP segment with P-P couplings

Fig. 3. Proposed H-joint SPSP for steel pipe sheet piles application

widen application areas of SPSP technology. The H-joint SPSP is expected to remediate problems of traditional joints in SPSPs. Constructional problems of $\mathrm{H}$-joint SPSP are addressed by conducting full-scale field and laboratory tests. Their mechanical and deformation behavior are assessed by centrifuge model tests and their experiment results are simulated using beam analysis method. Parametric studies using beam analysis are conducted to demonstrate the efficiency of using $\mathrm{H}$-joint SPSP and to estimate its joint efficiency for application in design of SPSP foundation structures.

\section{DEVELOPMENT OF H-JOINT STEEL PIPE SHEET PILES}

The authors have introduced and developed a technology in SPSP aimed at improving their performance and widening their application areas. They have developed a new $\mathrm{H}$-joint from a simple idea in which two steel pipes are connected by $\mathrm{H}$-steel section welded on them to form what is known as "H-joint SPSP", as shown in Fig. 3 and Photo 1 (Kimura et al., 2003, 2004). The H-steel section is what is referred to as the $\mathrm{H}$-joint and it will alternate in series with the traditional joints.

$\mathrm{H}$-joint SPSP can be described as "SPSP member with advantages in construction accuracy and in economic efficiency because two steel pipes are connected by welding of H-steel between them before construction" as shown in Fig. 3. The basic effects expected from application of H-joint SPSP compared to using SPSP with traditional joints are as follows:

(1) H-joint is completely waterproof.

(2) H-joint SPSP is environmentally friendly since the number of grouted joints is reduced by about $50 \%$.

(3) Short construction periods and reduction in operation costs are achieved because two steel pipe piles can be driven at the same time.

(4) H-joint SPSP have high bending rigidity because $\mathrm{H}$-steel section is welded rigidly and continuously against two steel pipes. 


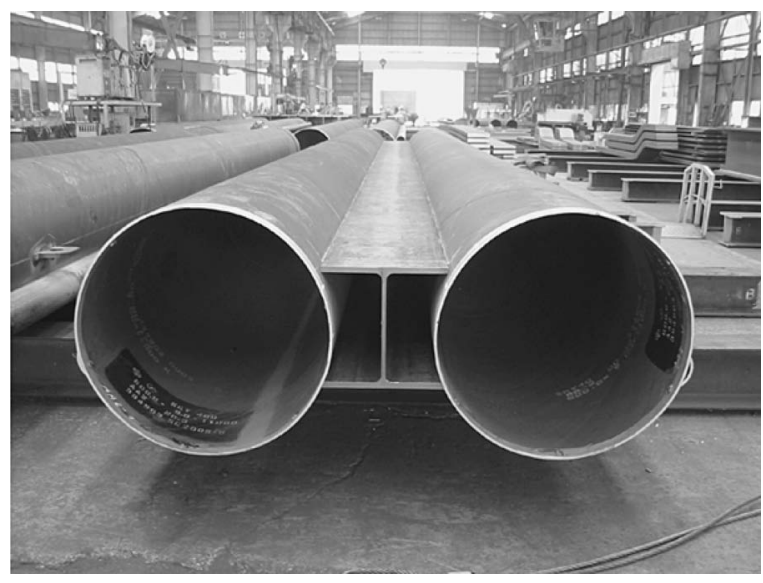

Photo 1. Photograph of developed H-joint SPSP

The H-joint SPSP is assembled by connecting two steep pipes, with traditional joints on either side, by welding an $\mathrm{H}$-steel between them. The assembly of H-joint SPSP can deal easily with SPSP structures with complicated shapes such as circular SPSP foundations by changing the angle at the position where two steel pipes with traditional joint and an $\mathrm{H}$-steel are welded.

\section{Construction Accuracy}

Construction accuracy of driving SPSP greatly affects the mechanical and hydraulic performance of SPSP foundation structures. However, there are not any specified standards for construction accuracy of SPSP in Japan. The construction accuracy of regular piles is regulated by the pile inclination angle of $1 / 100$, and the horizontal displacement at the pile head of $D / 4$ ( $D$ : diameter of pile) (Japan Road Association, 2002). If this regulation of regular piles was applied to the construction of SPSP, 1/100 of pile inclination means permitting a construction error of $100 \mathrm{~mm}$ at the bottom of an SPSP at a depth of $10 \mathrm{~m}$. Typically, the diameter of a traditional standard P-P joint pipe is $165.2 \mathrm{~mm}$, as shown in Fig. 1, therefore if an error of $100 \mathrm{~mm}$ was permitted, the $\mathrm{P}-\mathrm{P}$ joint pipes cannot interlock perfectly and they may crush altogether. Constructions of SPSP, thus, require higher driving accuracy in order to maintain verticality and achieve sound joint interlocking.

Field construction tests were conducted to check the practicality of driving $\mathrm{H}$-joint SPSP and to evaluate its construction accuracy. Three existing pile construction methods were used. They were vibro-pile hammer, jetting aided vibro-pile hammer and outer excavation methods, respectively.

The piles used in the tests had diameters $(\phi)$ of $900 \mathrm{~mm}$, thickness $(t)$ of $9 \mathrm{~mm}$ and lengths $(L)$ of $13 \mathrm{~m}$. An $\mathrm{H}$-steel whose dimensions were $400 \times 400 \times 13$ (web) $\times 21$ (flange) $\mathrm{mm}$ was welded against two such piles to form the $\mathrm{H}$-joint SPSP. In order to drive two piles at the same time, an original double head attachment with a chuck system (see Photo 2) was assembled at the bottom of vibro-pile hammer.

The field tests were conducted in Tokyo metropolitan

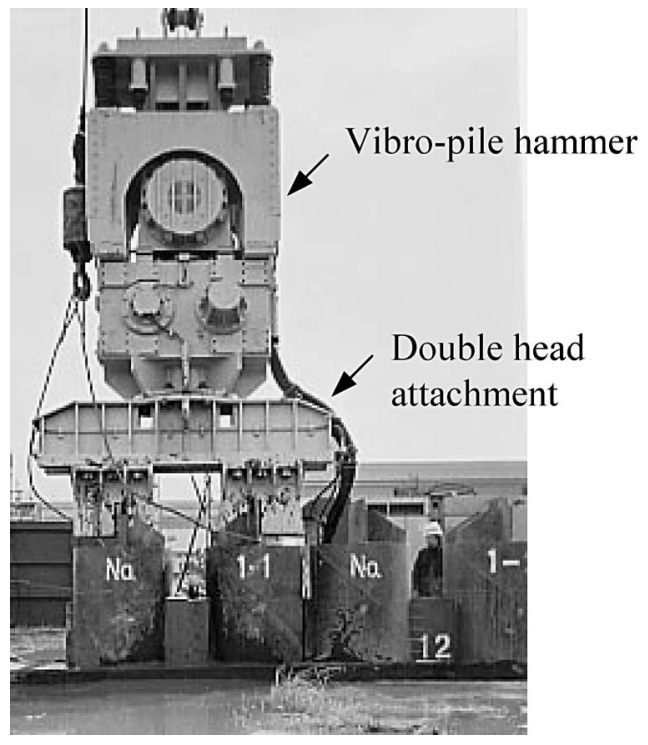

Photo 2. Vibro-pile hammer with double head attachment

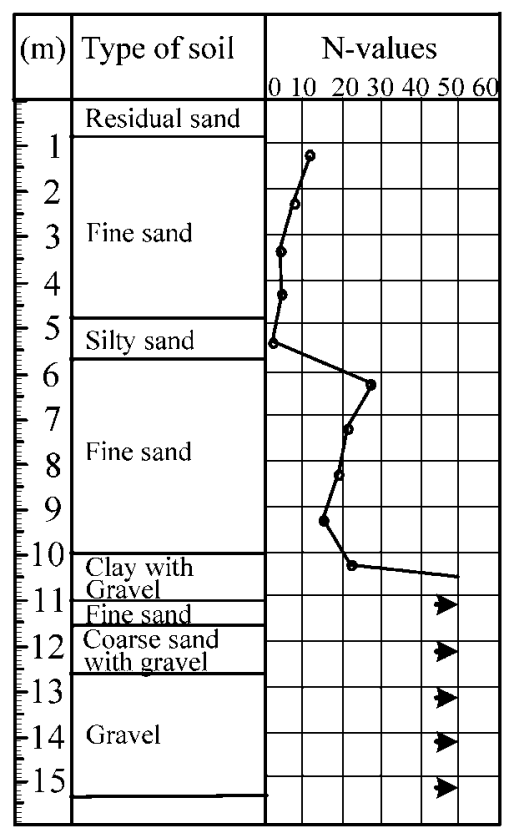

Fig. 4. Soil profile and standard penetration resistances in the boring at the site

area. Variability of subsurface conditions was assessed and identified by drilling one borehole. Standard penetration test (SPT) was carried out in the borehole to a depth of $15.36 \mathrm{~m}$. The soil characterization and $N$-values are shown in Fig. 4. The bearing layer lies at $11.0 \mathrm{~m}$ and the groundwater level is at $0.2 \mathrm{~m}$.

A vibro-pile hammer machine (ZERO-200MR) whose capacity was $150 \mathrm{~kW}$ was used. That capacity is equivalent to 1.5 times the capacity of vibro-pile hammers used to drive single piles of the same diameters $(\phi 900 \mathrm{~mm})$. Two H-joint SPSPs were installed by each of the three methods. The first H-joint SPSP was driven and then a second one was driven adjacent and connected to it by L-T joint. Vertical inclination of each SPSP was 
measured by an inclinometer inserted through a hollow square steel box welded in the inner face of the $\mathrm{H}$-steel flange as shown in Fig. 5.

The overall image of the field construction test for $\mathrm{H}$-joint SPSP is shown in Photo 3. Table 1 shows measured vertical inclinations in each case. The X-direction represents the inclination of the pile in the direction of construction and the $\mathrm{Y}$-direction refers to inclination of the pile in the side perpendicular to the direction of construction. The values in Table 1 are unit-less and the negative signs denote the direction of inclination with respect to the $\mathrm{X}-\mathrm{Y}$ axes as indicated in Fig. 5. High

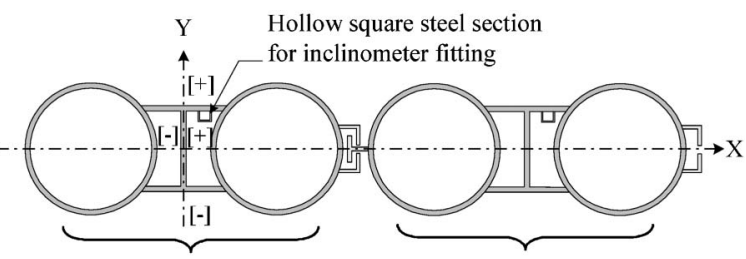

First driven H-joint SPSP Second driven H-joint SPSP

Fig. 5. Construction tests setup and inclination directions of $\mathbf{H}$-joint SPSP (with L-T joint)

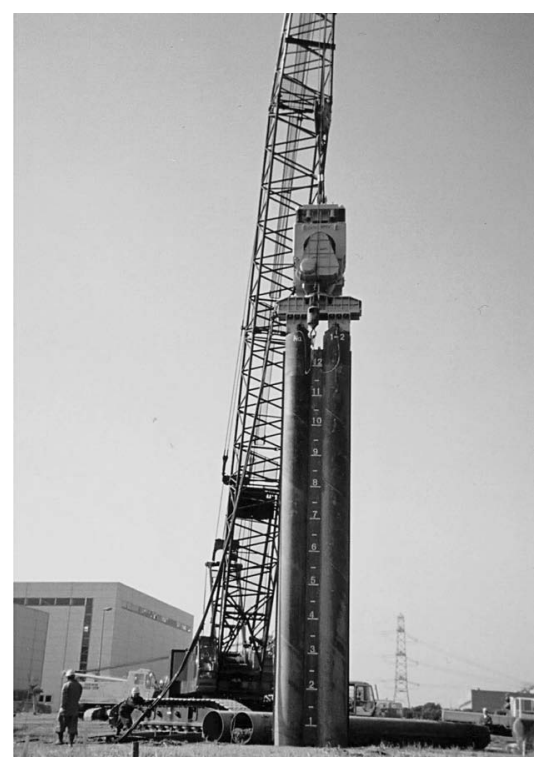

Photo 3. Overall situation regarding the field construction test for H-joint SPSP accuracies were achieved despite the field construction of $\mathrm{H}$-joint SPSP being the first time in the world and the operators lacking prior experience or knowledge. Pile inclination angle of $1 / 240,1 / 310$ and $1 / 550$ were achieved in vibro-pile hammer method, jetting aided vibro-pile hammer method and outer excavation method respectively. They are more accurate compared to maximum allowed inclination of ordinary piles which is 1/100 (Japan Road Association, 2002). The shape of the $\mathrm{H}$-jointed SPSP is thought to be responsible for the high accuracy.

An accurate installation management, that is construction accuracy of SPSP, is required, so that the SPSP structure constructed with the joint sections can ensure required mechanical and hydraulic performances. Therefore, the installation of SPSP must pay attention to their positions, inclinations, rotations and joint intervals, and it must ensure the required construction accuracy, especially the interlocked condition of joint sections must be elaborately managed because the resistance of the joint sections during the installation of SPSP greatly affects their construction accuracy and time. Generally, steel piles are made by welding spiraled steel sheets. This manufacturing process leaves spiral seams; therefore, a slight rotation is generated during installation of the piles. However, the rotation of SPSP is not permitted because they carry the traditional joint couplings welded on them. The SPSP can not rotate, even if it tends to rotate, the pull-push competition of each traditional joint section occurs instead causing inclination in the direction of construction. It is, therefore, difficult to maintain the original sound geometry of the traditional joints along the length of the pile. Tomisawa (2003) reported that the $25 \%$ of vertical loading energy for the installation of SPSPs in the field is consumed to the competition of each traditional joint section.

However, H-joint SPSP can be installed with high driving accuracy. This property is thought to originate from rigidly connecting, by welding 2 steel pipes and $\mathrm{H}$-steel into a unit and then driving the unit. Those shape so-called by the "glasses state" shown in Figs. 3 and 5 have the function of directional control. That is to say, the $\mathrm{H}$-joint SPSP can control the pile direction during their installation and the rotation and the inclination of the H-joint SPSP during installation are controlled. The

Table 1. Vertical inclinations at the pile heads

\begin{tabular}{|c|c|c|c|}
\hline \multirow{2}{*}{ Driving method } & \multirow{2}{*}{ Pile driving order } & \multicolumn{2}{|c|}{ Inclination in } \\
\hline & & $\mathrm{X}$-direction & Y-direction \\
\hline \multirow{2}{*}{ Vibro-pile hammer } & 1st driven & $-1 / 240$ & $-1 / 270$ \\
\hline & 2nd driven & $1 / 820$ & $-1 / 250$ \\
\hline \multirow{2}{*}{ Jetting aided vibro-pile hammer } & 1st driven & $1 / 1150$ & $1 / 380$ \\
\hline & 2nd driven & $1 / 1310$ & $1 / 310$ \\
\hline \multirow{2}{*}{ Outer excavation } & 1st driven & $-1 / 550$ & $-1 / 810$ \\
\hline & 2nd driven & $1 / 1350$ & $1 / 1440$ \\
\hline
\end{tabular}




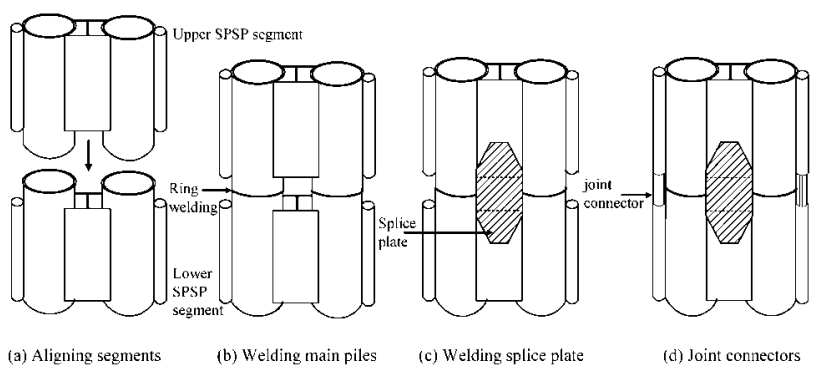

Fig. 6. In-situ procedure of joining H-joint SPSP segments during construction

H-joint SPSP enables ease of direction control, prevents rotation and minimizes inclination of the SPSP during installation. Consequently, it can been concluded that the $\mathrm{H}$-joint SPSP controls the accuracy of construction and guarantees sound geometrical condition of the traditional joints that must still alternate with the $\mathrm{H}$-joints.

\section{Proposed Field Segment Joint for H-joint SPSP Seg- ments}

Lengths of SPSP segments are extended by welding in the field. Currently, welding is accomplished with ease since only one pile with couplings on either side is involved. In the case of H-joint SPSP, it is easy to weld together the steel pipe pile portions and to weld together the flanges of $\mathrm{H}$-steel of two $\mathrm{H}$-joint SPSP segments; however it is difficult to weld together their webs. For this reason, a method of joining the $\mathrm{H}$-steel sections of two successive SPSP segments using a fillet welded splice plate is proposed.

In the proposed segment joint, the steel pipe sheet piles are first welded around their circumference to give the initial strength as shown in Fig. 6(b), and then the H-steel joint parts are connected by a fillet welded splice plate as shown in Fig. 6(c). The splice plate is welded onto the main piles and onto the $\mathrm{H}$-joint steel of two segments so that the joint is completely waterproof. A similar splice plate is also welded on the opposite side of the segment joint. Finally the $\mathrm{H}$-joint SPSP couplings are connected by welding an additional joint pipe connector as shown in Fig. 6(d).

The proposed segment joint is completely waterproof because it is welded, therefore only its bending strength is of concern. In this section, bending strength of the segment joint is evaluated by full-scale $\mathrm{H}$-joint SPSP bending tests. $\mathrm{H}$-joint SPSP with and that without the segment joint were tested in bending. Testing patterns were: (1) "H-joint SPSP without a segment joint" which was $8.3 \mathrm{~m}$ in length, $600 \mathrm{~mm}$ in pile diameter and has also an $\mathrm{H}$-steel whose sizes of $350 \times 350 \times 12(\mathrm{web}) \times 19$ (flange) $\mathrm{mm}$, and (2) "H-joint SPSP with a segment joint" which was $8.3 \mathrm{~m}$ in length, $600 \mathrm{~mm}$ in pile diameter and had also an $\mathrm{H}$-steel whose sizes of $350 \times$ $350 \times 12$ (web) $\times 19$ (flange) $\mathrm{mm}$. The $\mathrm{H}$-joint SPSP with segment joint is made by connecting two H-joint SPSP segments at the mid-span using a splice plate having 350 $\mathrm{mm}$ width, $1060 \mathrm{~mm}$ length and $22 \mathrm{~mm}$ thickness. The

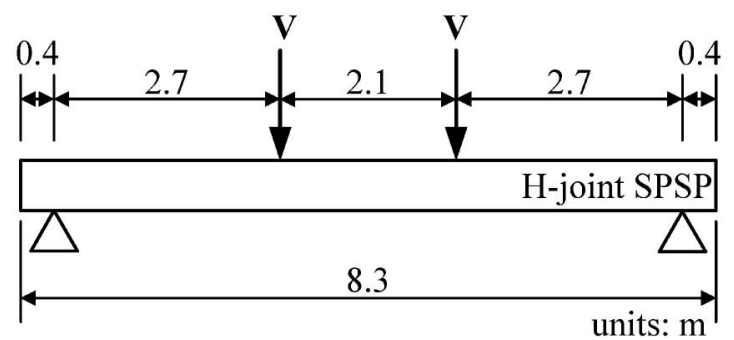

(a) H-joint SPSP without segment joint

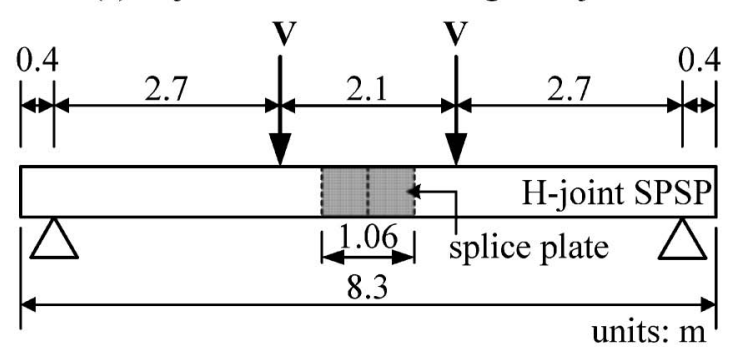

(b) H-joint SPSP with segment joint

Fig. 7. Bending tests for $\mathrm{H}$-joint SPSP with/without segment joint

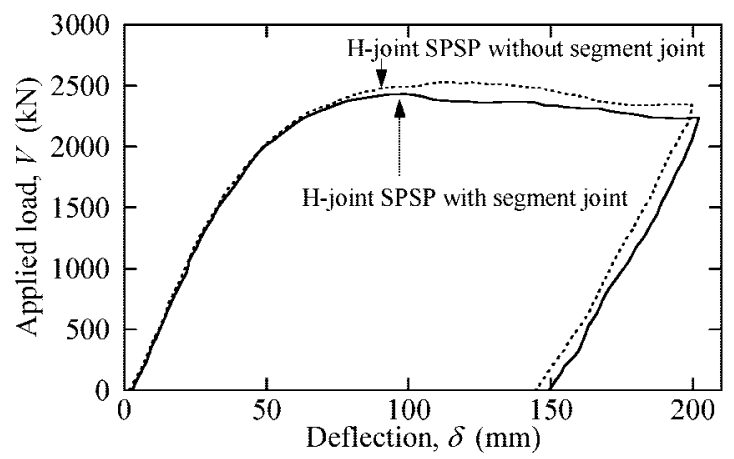

Fig. 8. Load-deflection relation from measured results

thickness of splice plate used was decided for its plastic section modulus for the central axis of steel pipe to exceed that of $\mathrm{H}$-steel used in the $\mathrm{H}$-joint SPSP. A $10 \mathrm{MN}$ capacity loading frame was used. The test $\mathrm{H}$-joint SPSP was supported horizontally at both ends and the load was applied simultaneously at two points (see Fig. 7). The distance between two loading points was $2.1 \mathrm{~m}(3.5 D)$, where $D$ is the pile diameter, and the length of the shear section was $4.5 D$. Vertical load $(V)$ was applied till failure and unloaded to zero load, the applied vertical load $(V)$ was measured by load cells, deflections $(\delta)$ and strains of the pipe pile part $\left(\varepsilon_{\mathrm{P}}\right)$ and $\mathrm{H}$-joint part $\left(\varepsilon_{\mathrm{H}}\right)$ were measured, respectively, by displacement and strain gauges mounted on both the pipe piles and the H-steel.

Relationship between applied load $(V)$ and deflection $(\delta)$ for H-joint SPSP with and without a segment joint are shown in Fig. 8. It is observed that irrespective of existence of a segment joint, the $V$ - $\delta$ relation is similar and the maximum bending strengths are approximately equal. It can be judged that proposed segment joint structure has as much bearing strength as a continuous $\mathrm{H}$-joint SPSP. Strain distributions on extreme tension edges of main piles $\left(\varepsilon_{\mathrm{P}}\right)$ and that on extreme tension edges 

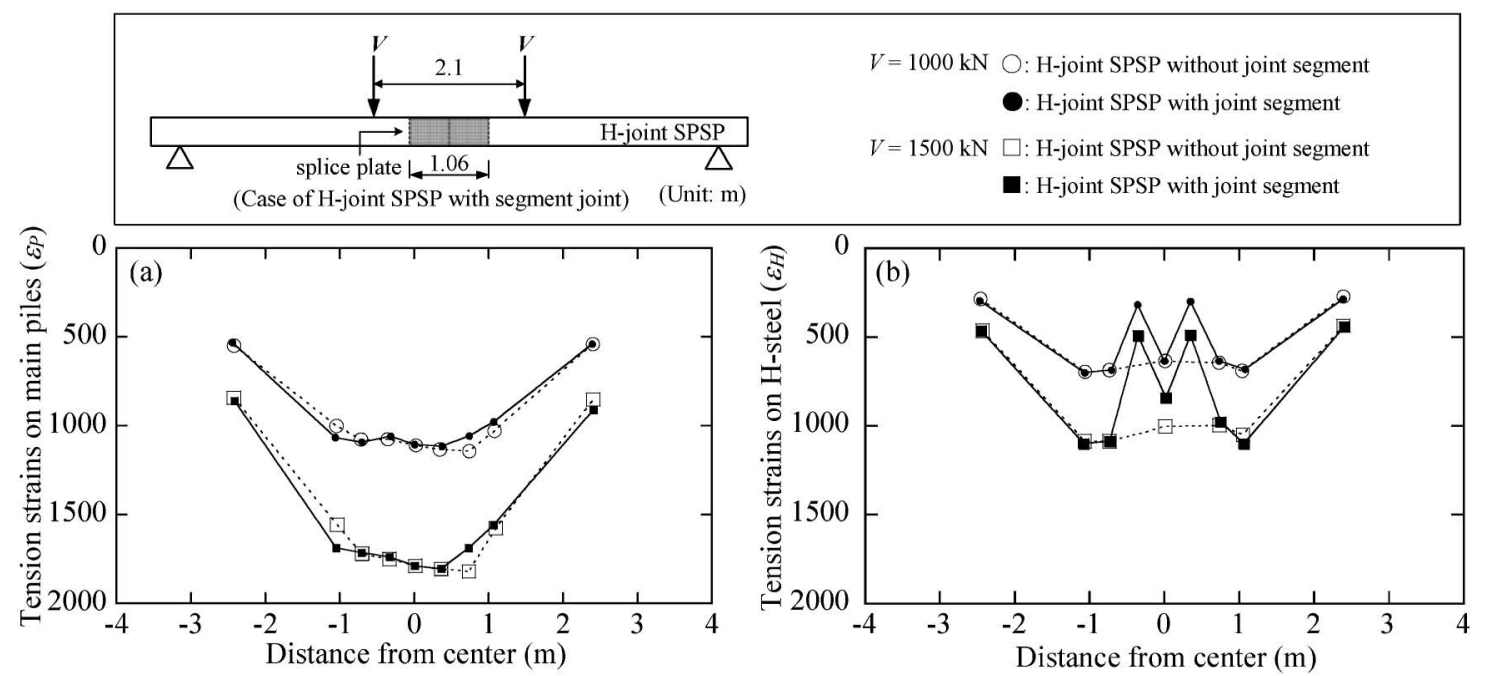

Fig. 9. Strain distribution on (a) main piles only and (b) H-steel section in H-joint SPSP 6 with/without segment joint

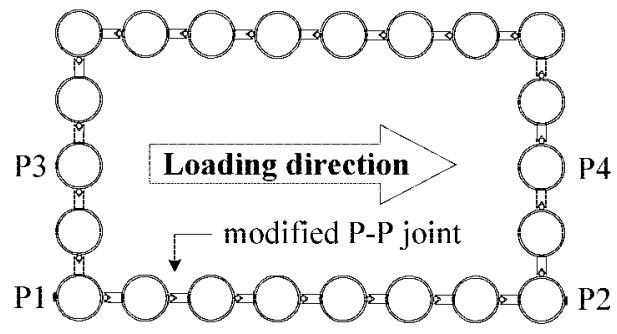

(a)

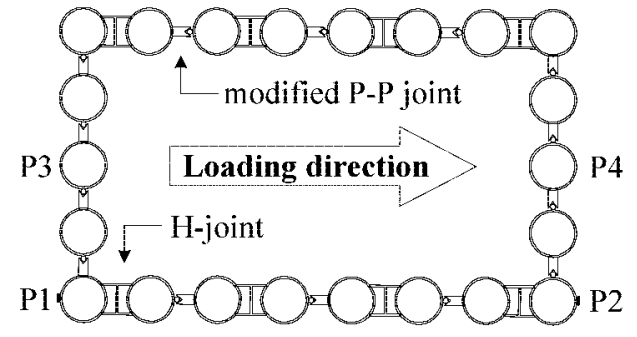

(b)

Fig. 10. Rectangular SPSP model foundations (a) Case-I and (b) Case-II

of H-steel section $\left(\varepsilon_{\mathrm{H}}\right)$ are shown in Fig. 9. It is observed that the strain distributions on the extreme tension edges of main piles are approximately equivalent to those of the segment joint ( see Fig. 9(a)). Therefore, the ring welding on each pile and splice plate welded on the $\mathrm{H}$-steel which are conducted to the H-joint SPSP with a segment joint effectively resists the applied vertical load $(V)$ without contributing to strain increase in the main piles. For the strain distributions of the $\mathrm{H}$-steel section on the $\mathrm{H}$-joint SPSP with a segment joint, the strain in the adjacent welding position between $\mathrm{H}$-steel and splice plate (about $\pm 30 \mathrm{~cm}$ from the centre of the splice plate) is smaller than that of H-joint SPSP without a segment joint (see Fig. 9(b)). This tendency clearly shows that the splice plate welded on the $\mathrm{H}$-steel can resist the applied vertical load $(V)$ in collaboration with the $\mathrm{H}$-steel itself. At the $\mathrm{H}$-joint SPSP with a segment joint, the strain value of the splice plate single position at which the $\mathrm{H}$-steel does not exist exhibits equivalent response as the $\mathrm{H}$-joint SPSP without a segment joint. It is found that the resistance property for the bending of the splice plate single position is equivalent to that in the $\mathrm{H}$-steel section. Consequently, the results of full-scale $\mathrm{H}$-joint SPSP bending tests clearly show that the proposed field segment joint for $\mathrm{H}$-joint SPSP using a welded splice plate is strong and effective in bending, hence the proposed segment joint methods is recommended for joining the H-joint SPSPs.

\section{EVALUATION OF MECHANICAL STABILITY OF H-JOINT SPSP FOUNDATIONS}

Mechanical and deformation behavior of SPSP foundations which are constructed using $\mathrm{H}$-joints and traditional P-P joints is studied by testing model SPSP foundations under centrifuge conditions. A rectangular $\mathrm{H}$-joint SPSP model foundation was tested in a beam centrifuge machine whose effective radius was $3.80 \mathrm{~m}$ (Imamura et al., 1998) under static lateral loading to assess its mechanical and deformation behavior. Furthermore, behavior of the rectangular H-joint SPSP model foundation was compared with that of a rectangular SPSP model foundation which had P-P joints only.

\section{Model Foundations and Ground Profile}

Tested rectangular SPSP model foundation which had P-P joints only and the rectangular H-joint SPSP model foundation were designated Case-I and Case-II respectively, as shown in Fig. 10. Their properties are given in Table 2. Case-I had P-P joints only. Case-II had 8 $\mathrm{H}$-joints in the side parallel to the loading direction and only P-P joints in the side perpendicular to the loading direction. The P-P joint in model scale was made as shown in Fig. 11 with consideration of sliding and rotational characteristics of prototype P-P joint and ease in designing and fabricating in model scale. Pile material 
was brass whose modulus of elasticity $(E)$ is $1.1 \times 10^{5}$ $\mathrm{MPa}$. Total moment of inertia $\left(I_{z}\right)$ for the foundations were obtained according to Eq. (1) assuming that the joint efficiency $(\mu)$ equals 1.0 .

$$
E_{\mathrm{s}} I_{\mathrm{z}}=E_{\mathrm{s}}\left(\sum_{i=1}^{n_{1}} I_{\mathrm{oi}}+\mu \sum_{i=1}^{n_{1}} A_{\text {oi }} y_{\mathrm{i}}^{2}\right)
$$

where, $I_{\mathrm{oi}}=$ moment of inertia of each pile (pile $i$ ) about its own local axis; $A_{\mathrm{i}}=$ cross sectional area of pile $i ; y_{\mathrm{i}}=$ distance from the axis of an individual pile $i$ to the global axis of the foundation; $n_{1}=$ number of piles.

Model ground was dry Toyoura sand and its properties are as such; specific gravity $\left(G_{\mathrm{s}}\right)$ of 2.64 , dry unit weight $\left(\gamma_{\mathrm{d}}\right)$ of $16.11 \mathrm{kN} / \mathrm{m}^{3}$, void ratio $(e)$ of 0.638 , minimum void ratio $\left(e_{\min }\right)$ of 0.540 , maximum void ratio $\left(e_{\max }\right)$ of

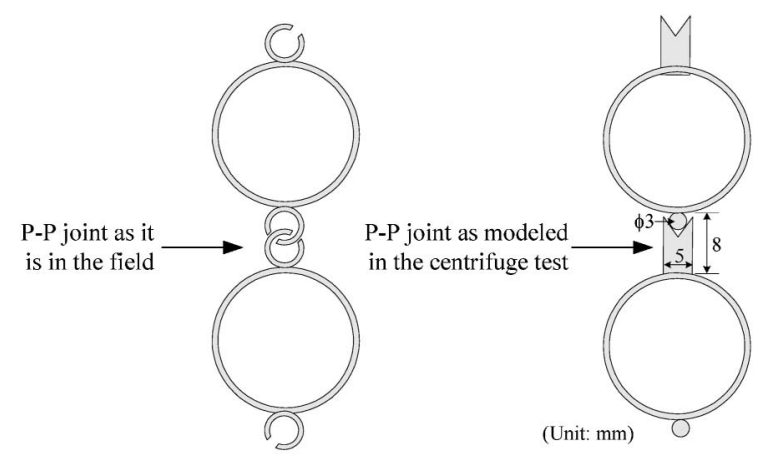

(a) Standard P-P joint shape

(b) Modified P-P joint shape

Fig. 11. P-P joint modeling in the centrifuge test

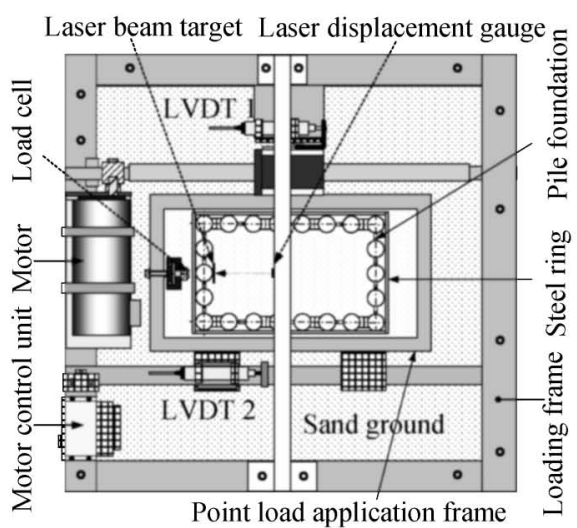

(a) Plane view
0.982 , and internal angle of friction $(\phi)$ of $38^{\circ}$. A line pouring hopper was used to form the ground achieving a homogeneous ground with a relative density $\left(D_{\mathrm{r}}\right)$ of $88 \%$. $490 \mathrm{~mm}$ of the foundation length was embedded in the ground leaving a free length of $50 \mathrm{~mm}$ above the ground. A lateral point load was applied at $35 \mathrm{~mm}$ from the ground surface.

\section{Testing System}

The test chamber shown in Fig. 12 measured $600 \times 600$ $\mathrm{mm}$ in plan with a depth of $500 \mathrm{~mm}$. The piles were fixed at the base using a base plate and free at the head. A steel ring indicated in Fig. 12(a) was placed around the foundation top only for the purpose of aligning the piles in the SPSP foundation during ground making and to transmit the applied lateral point load during the test to all piles. The lateral displacement of the foundation head was measured by two linear variable differential transformers (LVDT-1 and LVDT-2) and laser displacement gauges. Applied lateral load $(P)$ was measured by a load cell. At $30 \mathrm{G}$, load was applied at a speed of $1 \mathrm{~mm} / \mathrm{min}$. Strain gauges were fixed on the leading and trailing sides of P1, P2, P3 and P4 (see Fig. 10).

\section{Lateral Bearing Capacity of $H$-joint SPSP}

Relationships in prototype scale are shown in Fig. 13 for applied lateral load $(P)$ and normalized displacement $(\delta / D)$, where measured displacement $(\delta)$ is divided by the diameter of steel pipe $(D)$. Two tests were done on each model under the same test conditions. It is observed that the lateral bearing capacity of Case-II is larger than that

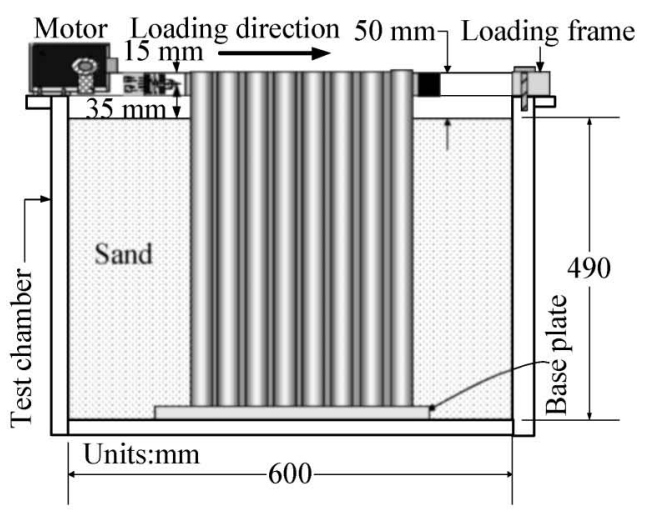

(b) Cross section

Fig. 12. Foundation loading system in the centrifuge test

Table 2. Properties of the rectangular centrifugal test models

\begin{tabular}{c|l|c|c|c|c|c}
\hline \multirow{2}{*}{ Test } & Scale & $\begin{array}{c}\text { Length } \\
(\mathrm{mm})\end{array}$ & $\begin{array}{c}\text { Diameter } \\
(\mathrm{mm})\end{array}$ & $\begin{array}{c}\text { Thickness } \\
(\mathrm{mm})\end{array}$ & $\begin{array}{c}\text { Foundation size } \\
(\mathrm{m})\end{array}$ & $\begin{array}{c}\text { Flexural rigidity } \\
\left(\mathrm{kN} \cdot \mathrm{m}^{2}\right)\end{array}$ \\
\hline \multirow{3}{*}{ Case-I } & Model & 540 & 25.4 & 1.0 & $0.275 \times 0.168$ & $1546(\mu=1)$ \\
\cline { 2 - 7 } & Prototype & 16200 & 762 & 30 & $8.25 \times 5.04$ & $1.3 \times 10^{9}$ \\
\hline \multirow{2}{*}{ Case-II } & Model & 540 & 25.4 & 1.0 & $0.275 \times 0.168$ & $1700(\mu=1)$ \\
\cline { 2 - 7 } & Prototype & 16200 & 762 & 30 & $8.25 \times 5.04$ & $1.4 \times 10^{9}$ \\
\hline
\end{tabular}


of Case-I at the same displacements through from 0 to $10 \%$ in the normalized displacement. Their average lateral bearing capacity at a normalized displacement of $10 \%$ for Case-I and Case-II are $4413 \mathrm{kN}$ and $6332 \mathrm{kN}$ respectively. Effect of $\mathrm{H}$-joint is defined by dividing the lateral bearing capacity of Case-II by that of Case-I. Case-II is found to be 1.3 times stronger than Case-I at a normalized displacement of $10 \%$. The increased capacity of Case-II is attributed to the welded $\mathrm{H}$-joints which increase the overall bending rigidity of the foundations while the weak response of Case-I is thought to be due to occurrence of vertical shear movements at the joints. It can be concluded that the $\mathrm{H}$-joint SPSP has a higher lateral bearing capacity than SPSP with traditional joints; it derives its strength from the welded $\mathrm{H}$-steel connection.

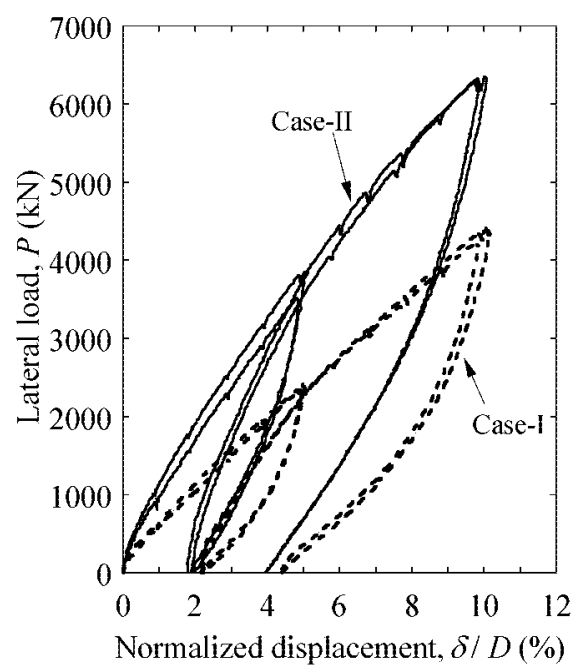

Fig. 13. Relationship between applied lateral load $(P)$ and normalized displacement $(\delta / D)$ for Case-I and Case-II

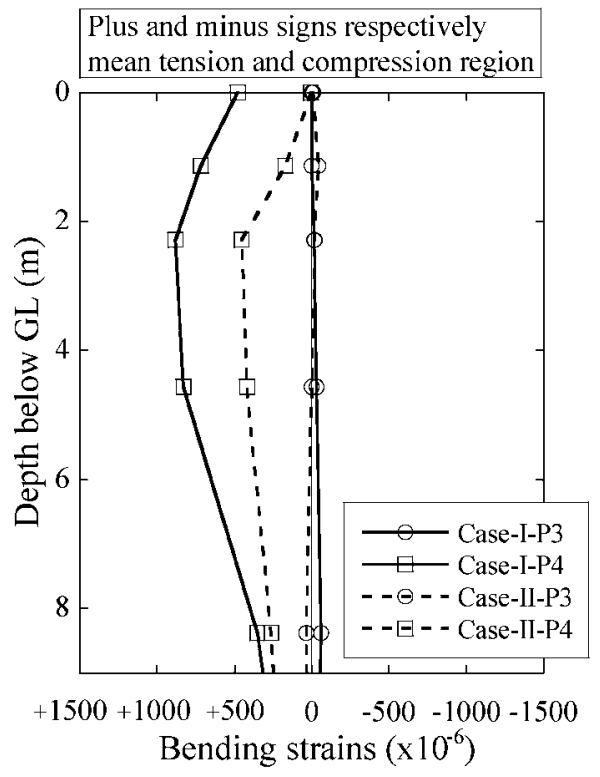

(a) Corner piles
Bending strains in Piles P1, P2, P3 and P4 measured at lateral load of $4400 \mathrm{kN}$ are plotted against depth in Fig. 14. Tension side being the loaded face experienced higher strains than the compression side. This is thought to be because the head of the foundation was free, that is, there was no direct load transfer media from pile P1 to pile P2 and from pile P3 to pile P4. Applied load is transmitted through the perimeter piles therefore most of it is lost along this transmission path. The response of $\mathrm{H}$-joint SPSP foundations to deformation is better compared with the response of SPSP foundations with traditional joints.

Based on results from the centrifuge experiments, $\mathrm{H}$-joint SPSP is stronger than SPSP with traditional joints irrespective of the loading direction. That means the required steel pipe pile diameter will be smaller and the sectional size of the foundation can be reduced hence it would be cost effective. H-joint SPSP foundations undergo less deformation when under lateral load than SPSP foundations with P-P joints.

\section{APPLICABILITY OF H-JOINT SPSP BASED ON BEAM ANALYSIS}

Generals on Beam Analysis

The designs for SPSP foundations are categorized into two methods as shown in Fig. 15. They are Method (1) referred to as beam analysis by finite length beam on an elastic bed, and Method (2) referred to as beam analysis by virtual open caisson beam, respectively (Public Works Research Institute, 1977; Japanese Association for Steel Pipe Piles, 1999). Generally, Method (1) is widely used by SPSP designers because it is relatively simple to use.

In Method (1), firstly, the total rigidity of the overall SPSP foundation is estimated by reducing the moment of inertia using the joint efficiency $(\mu)$ as in (Eq. (1)) to take

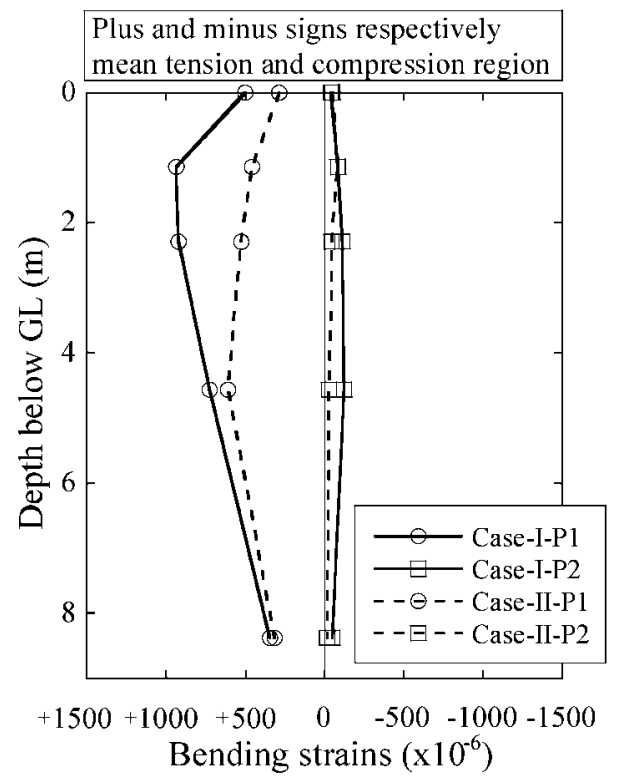

(b) Centre piles

Fig. 14. Strain distribution along Pile P1, P2, P3 and P4 at lateral load of $4400 \mathrm{kN}$ 


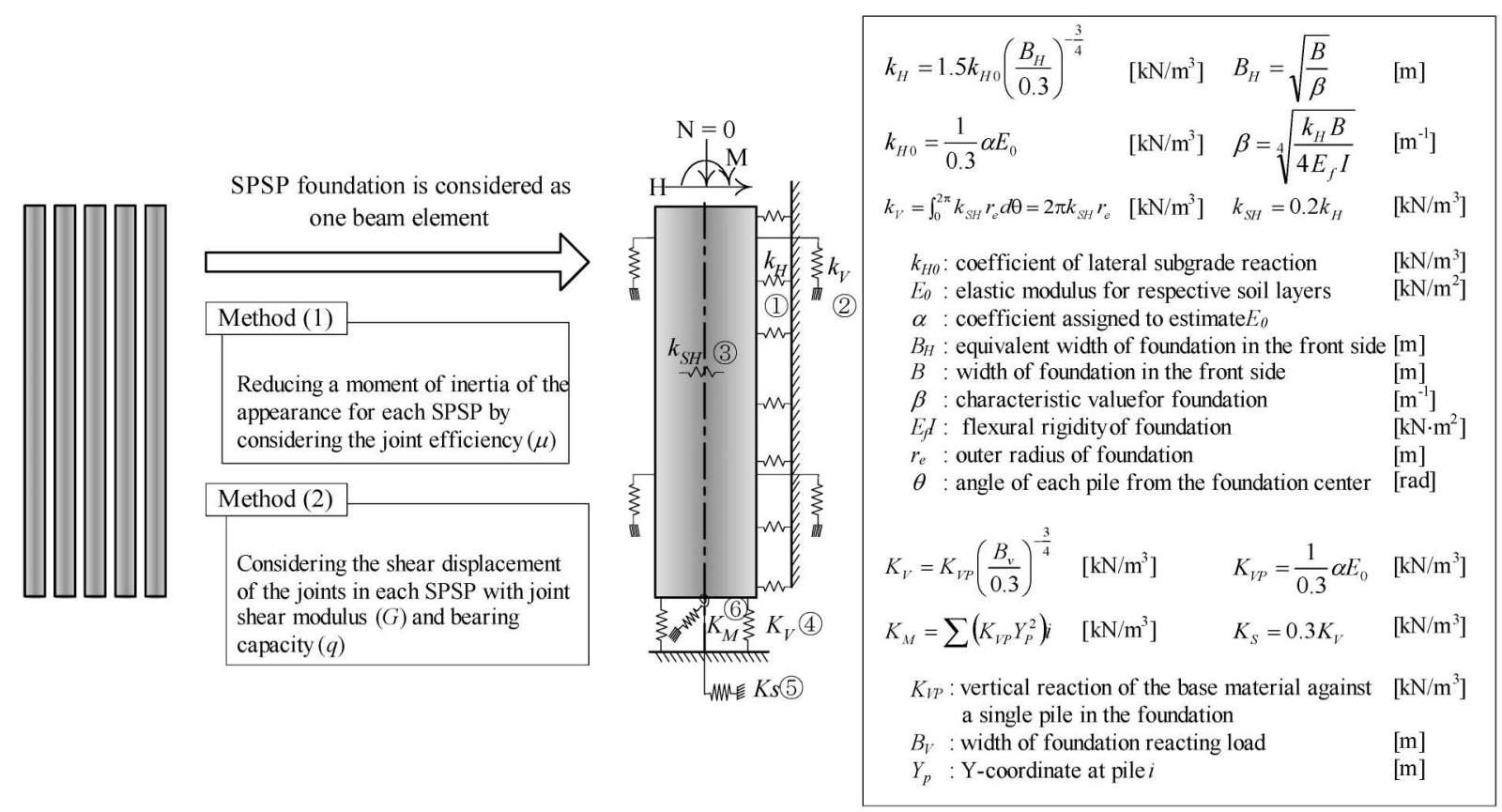

Fig. 15. Conceptual diagram of design methods on SPSP foundations (Public Works Research Institute, 1977; Japanese Association for Steel Pipe Piles, 1999)

into account joint movements. Secondly, the mechanical characteristics of overall SPSP foundation are easily evaluated in Method (1) by loading the subgrade reactions, as shown in Fig. 15, by the overall SPSP foundation whose total rigidity is estimated.

In Method (2), the total rigidity of overall SPSP foundation is first estimated by considering the shear displacement of the joints in each SPSP with joint shear modulus $(G)$ and bearing capacity $(q)$. Secondly, Method (2) evaluates the mechanical characteristics of overall SPSP foundation using the subgrade reaction model shown in Fig. 15 as well as the case of Method (1). In this section, simulation of centrifuge experimental results, reduction of cross sectional dimensions of foundations using $\mathrm{H}$-joint SPSP and estimation of joint efficiency for design of H-joint SPSP have been conducted by mutually using Method (1) and Method (2).

\section{Simulation of Centrifuge Experiment Results}

The beam analysis by Method (2) was used to simulate the behavior of $\mathrm{H}$-joint SPSP foundation in the centrifuge experimental results. Soil and P-P joints were modeled as springs while piles were treated as beams. In order to analyze $\mathrm{H}$-joint SPSP foundations, each set of $\mathrm{H}$-joint SPSP was treated as one beam because they are welded together and bending rigidity $(E I)$ of that beam was the combined rigidity of the welded components of the H-jointed piles. The P-P joint used in the centrifuge tests was a modified version as shown in Fig. 11, therefore, its joint shear modulus $(G)$ and bearing capacity $(q)$ had to be estimated. In this study, $G$ and $q$ used for the modified P-P joint was $8140 \mathrm{kN} / \mathrm{m}^{2}$ and $1.1 \mathrm{kN} / \mathrm{m}$, respectively, obtained from a joint shear test on the modified P-P joint conducted by Too et al. (2004).
In estimating pile-soil springs in the horizontal direction, centrifuge experiment results of the single pile were used to estimate the coefficient of horizontal subgrade reaction $\left(k_{\mathrm{H}}\right)$ against the foundations (Too et al., 2004). As their report, $k_{\mathrm{H}}$ at a displacement of $1 \%$ and $0.2 \%$ was taken as the value for the horizontal soil spring at the top and bottom of the foundation respectively, and $k_{\mathrm{H}}$ (spring (1) in Fig. 15) at the top and bottom were, respectively, estimated to be $3800 \mathrm{kN} / \mathrm{m}^{3}$ and $9000 \mathrm{kN} /$ $\mathrm{m}^{3}$. Vertical shear between the foundation and the soil $\left(k_{\mathrm{v}}\right)$ (spring (2) in Fig. 15) was estimated by carrying out a pile-soil shear test, and the detailed method of pile-soil shear test is contained in Too et al. (2004). Pile-soil shear on the sides of the foundation in horizontal direction ( $\left.k_{\mathrm{SH}}\right)$ (spring (3) in Fig. 15) was estimated as 0.2 times $k_{\mathrm{H}}$.

In order to estimate pile-soil springs at the foundation base during design of SPSP foundation, the elastic modulus of the bearing soil $\left(E_{0}\right)$ is required. However, in this study, the ends of piles in the foundation terminated onto steel base as shown in Fig. 12(b), therefore, elastic modulus $\left(E_{\mathrm{s}}\right)$ of steel which is $2.1 \times 10^{8} \mathrm{kN} / \mathrm{m}^{2}$ was used as the elastic modulus of the bearing soil $\left(E_{0}\right)$. As shown in Fig. 15, the vertical base springs $\left(K_{\mathrm{V}}\right)$, the horizontal base shear springs $\left(K_{\mathrm{S}}\right)$ and rotation springs $\left(K_{\mathrm{M}}\right)$, which are designated (4), (5) and (6) respectively, were estimated using the empirical equations proposed by Public Works Research Institute (1977) and Japanese Association for Steel Pipe Piles (1999).

Calculated and measured parameters for joints, soil and piles are shown in Table 3. Static lateral point load $(P)$ was applied at $1.05 \mathrm{~m}$ above the ground surface for the rectangular foundations. The loads were applied in steps of $250 \mathrm{kN}$ to a maximum load equal to lateral bearing capacities of each case at normalized displace- 
Table 3. Calculated and measured parameters for joints, soil and piles

\begin{tabular}{|c|c|c|}
\hline Foundation type & \multicolumn{2}{|c|}{ Rectangular } \\
\hline Foundation identity & Case-I & Case-II \\
\hline $\begin{array}{l}\text { Soil parameters } \\
\text { Coefficient of horizontal subgrade reaction, } k_{\mathrm{H}}\left(\mathrm{kN} / \mathrm{m}^{3}\right) \\
\text { Vertical shear between foundation and soil, } k_{\mathrm{V}}\left(\mathrm{kN} / \mathrm{m}^{3}\right) \\
\text { Horizontal shear between side of foundation and soil, } k_{\mathrm{SH}}\left(\mathrm{kN} / \mathrm{m}^{3}\right) \\
\text { Base vertical spring, } K_{\mathrm{V}}\left(\mathrm{kN} / \mathrm{m}^{3}\right) \\
\text { Base horizontal shear spring, } K_{\mathrm{s}}\left(\mathrm{kN} / \mathrm{m}^{3}\right) \\
\text { Base rotation spring, } K_{\mathrm{M}}(\mathrm{kN} \cdot \mathrm{m} / \mathrm{rad})\end{array}$ & $\begin{array}{l}3800 \text { at the top } \\
9000 \text { at the bottom } \\
79860 \\
760 \text { at the top } \\
1800 \text { at the bottom } \\
9.6 \times 10^{7} \\
2.9 \times 10^{7} \\
1.27 \times 10^{11}\end{array}$ & $\begin{array}{l}3800 \text { at the top } \\
9000 \text { at the bottom } \\
78830 \\
760 \text { at the top } \\
1800 \text { at the bottom } \\
9.6 \times 10^{7} \\
2.9 \times 10^{7} \\
1.27 \times 10^{11}\end{array}$ \\
\hline $\begin{array}{l}\text { Foundation parameters } \\
\text { Sectional area of foundation }\left(\mathrm{m}^{2}\right) \\
\text { Sectional 2nd moment of inertia }\left(\mathrm{m}^{4}\right) \\
\text { Sum of sectional moment of inertia }\left(\mathrm{m}^{4}\right)\end{array}$ & $\begin{array}{l}2.385 \\
19.6 \\
0.27\end{array}$ & $\begin{array}{l}2.412 \\
19.3 \\
0.66\end{array}$ \\
\hline
\end{tabular}

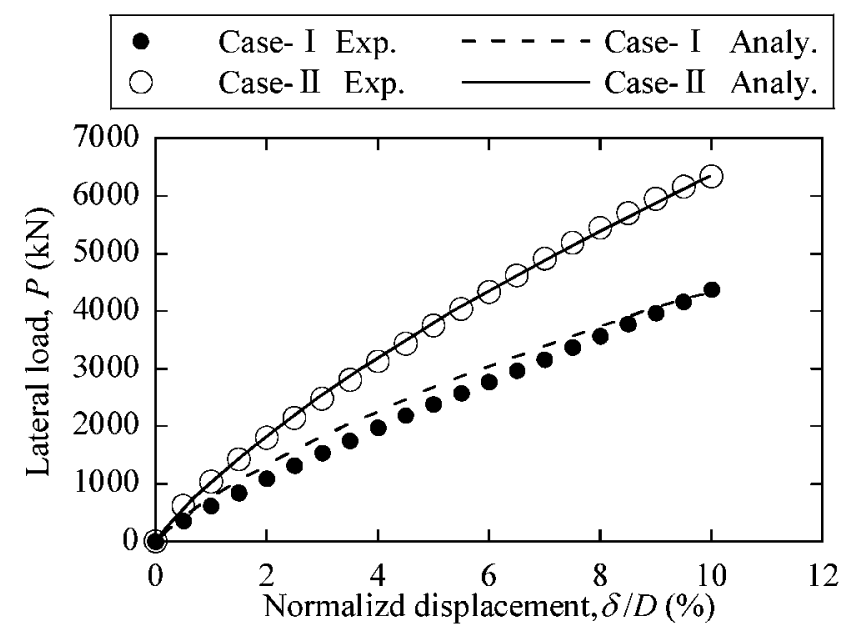

Fig. 16. $P-\delta / D$ relations from experiments and analysis for foundations

ment $(\delta / D)$ of $10 \%$ of which the displacement $(\delta)$ was divided by the diameter of steel pipe $(D)$ and the resulting foundation-head displacements were plotted versus the lateral loads causing them. Analyses and experiment results are compared in Fig. 16. $P-(\delta / D)$ results from analysis are in close agreement with centrifuge model test results in all cases which validate the initial assumption that the $\mathrm{H}$-jointed piles can be modeled as a beam. It shows that centrifuge tests can adequately model the behavior of H-joint SPSP structures, and confirms that the beam analysis approach by Method (2) can be applied in H-joint SPSP structures.

\section{Reduction of Cross Sectional Dimensions of Foundations Using H-Joint SPSP}

A parametric study was done to show that the cross sectional size of a foundation can be reduced when using H-joint SPSP so that the amount of steel material required is less and that construction in confined areas and near existing structures is possible besides a save in installation time.

The lateral bearing capacity of a circular (diameter $10.35 \mathrm{~m}$ fixed) SPSP foundation with P-P joints only (P-P joint SPSP foundation) as shown in Fig. 17 was compared with another circular SPSP foundation, estimated through trial and error, which had $\mathrm{H}$-joints alternating with P-P joints (H-joint SPSP foundation) as shown in Fig. 17. The diameter was through trial and error in the sense that, at first, the lateral bearing capacity of a circular H-joint SPSP foundation whose diameter was approximately equal to the diameter $(10.35 \mathrm{~m})$ of the P-P joint SPSP foundation was estimated. Its capacity was by far larger than that of the P-P joint SPSP foundation therefore the diameter of the H-joint SPSP was reduced and its lateral bearing capacity estimated again. The size reduction and recalculation of the corresponding lateral bearing capacity was repeated for the $\mathrm{H}$-joint SPSP until the lateral bearing capacity was such that it is approximately equal to that of the circular P-P joint SPSP foundation with diameter of $10.35 \mathrm{~m}$. The foundation had 26 piles and the piles constituting the foundations had the diameter $(D)$ of $1000 \mathrm{~mm}$. Standard P-P joints $(\phi 165.2 \mathrm{~mm})$ whose shear modulus $(G)$ and joint bearing capacity $(q)$ were $3.0 \times 10^{5} \mathrm{kN} / \mathrm{m}^{2}$ and 100 $\mathrm{kN} / \mathrm{m}$ respectively (Katayama et al., 1993), were used. The lateral bearing capacities were estimated using beam analysis method that models the foundation as virtual open caisson beam considering shear displacements of the joints (Method (2)).

The ground considered in the analysis was that for one of construction sites in Tokyo Metropolitan for Highway Bridges. The field test results from one such site were used in this study. Soil profile, $N$-values and elastic modulus of the respective soil layers are shown in Fig. 18. Elastic modulus $\left(E_{0}\right)$ of the bearing soil layer is $5 \times 10^{4} \mathrm{kN} / \mathrm{m}^{2}$. The top soil is at 0 to $2 \mathrm{~m}$ layer, sand is at 2 to $10 \mathrm{~m}$ underlain by clay at a depth of 10 to $46 \mathrm{~m}$ followed by a negligible thickness of humic soil which is underlain by sand at a depth of $46 \mathrm{~m}$ and beyond. $N$-values of the top 
Table 4. Properties of the circular H-joint and P-P joint SPSP foundations

\begin{tabular}{l|c|c|c|c|c}
\hline & $\begin{array}{c}\text { Diameter } \\
(\mathrm{mm})\end{array}$ & $\begin{array}{c}\text { Pile size } \\
(\mathrm{mm})\end{array}$ & $\begin{array}{c}\text { P-P joint size } \\
(\mathrm{mm})\end{array}$ & $\begin{array}{c}\text { H-joint size } \\
(\mathrm{mm})\end{array}$ & $\begin{array}{c}\text { Flexural rigidity } \\
\left(\mathrm{kN} / \mathrm{m}^{2}\right)\end{array}$ \\
\hline $\begin{array}{l}\text { Circular SPSP foundation } \\
\text { which has P-P joints only }\end{array}$ & 10350 & $1000 \times \mathrm{t} 12$ & $165.2 \times \mathrm{t} 11$ & $\begin{array}{c}\text { Sectional area } \\
\text { of steel } \\
\left(\mathrm{m}^{2}\right)\end{array}$ & $3.89 \times 10^{9}$ \\
\hline $\begin{array}{l}\text { Circular H-joint SPSP } \\
\text { foundation }\end{array}$ & 8850 & $1000 \times \mathrm{t} 12$ & $165.2 \times \mathrm{t} 11$ & $\mathrm{H} 488 \times 300 \times 11 \times 18$ & $2.47 \times 10^{9}$ \\
\hline
\end{tabular}

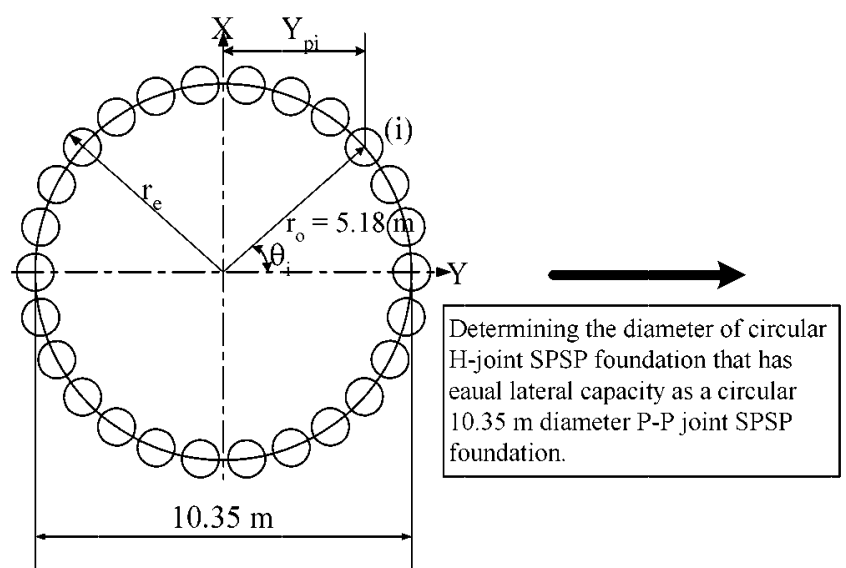

(a) Circular SPSP foundation which has P-P joints only

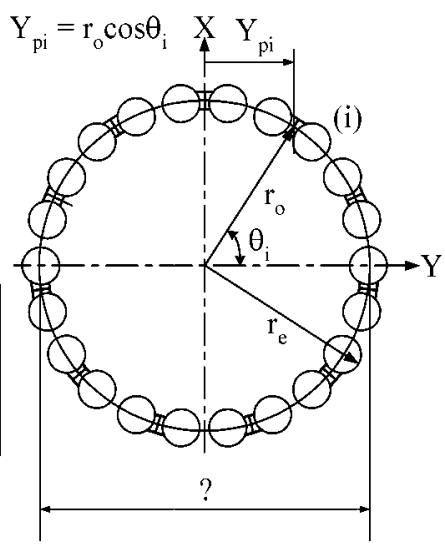

(b) Circular H-joint SPSP foundation

Fig. 17. Schematic diagram used to estimate the size of a circular H-joint SPSP foundation which has approximately equal lateral bearing capacity as a circular $10.35 \mathrm{~m}$ diameter P-P joint SPSP foundation

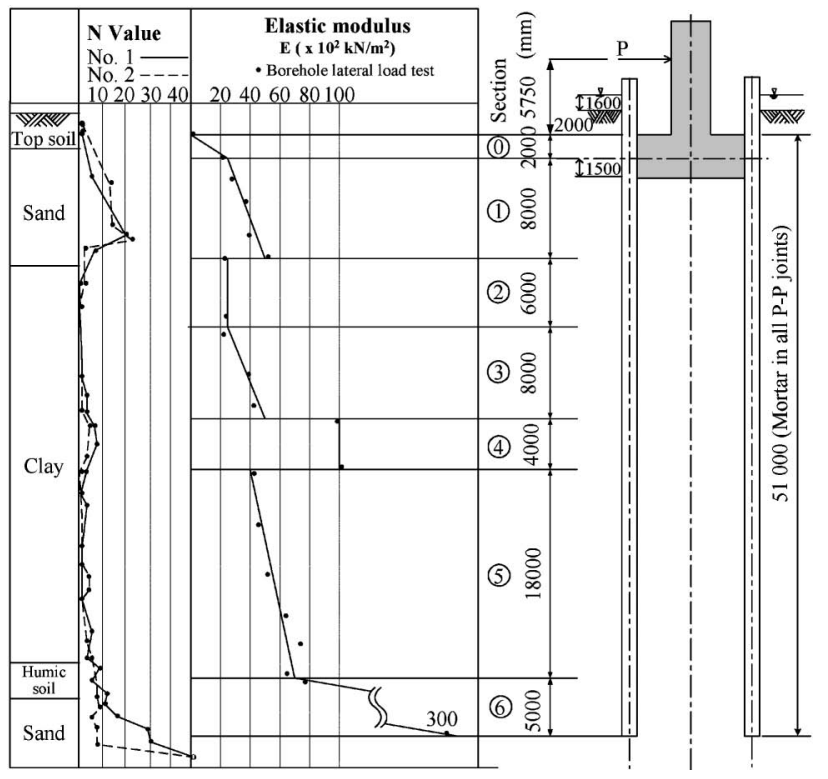

Fig. 18. Soil profile, $N$ values and elastic modulus of each layer

sand ( 2 to $10 \mathrm{~m}$ ) and clay layers are below 50 .

Soil springs on the sides of the foundation were estimated using elastic modulus values shown in Fig. 18. It was assumed that coefficients of horizontal subgrade reaction $\left(k_{\mathrm{H}}\right)$ in front and behind the foundation are equal. The horizontal subgrade reaction $\left(k_{\mathrm{H}}\right)$, pile-soil shear spring $\left(k_{\mathrm{V}}\right)$ and the shear ground resistance in the horizontal direction around the outer surface of the foundation $\left(k_{\mathrm{SH}}\right)$, were estimated respectively using the empirical equations proposed by Public Works Research Institute (1977) and Japanese Association for Steel Pipe Piles (1999), as shown in Fig. 15.

Three springs, those vertical subgrade reaction $\left(K_{\mathrm{V}}\right)$, horizontal shear between the bearing soil layer and the base of the foundation $\left(K_{\mathrm{S}}\right)$ and rotation at the base of the foundation $\left(K_{\mathrm{M}}\right)$, were also estimated from the empirical equations shown in Fig. 15. Calculated soil, joint and foundation parameters were used in the analysis. Point lateral load $(P)$ was applied at $7.75 \mathrm{~m}$ from the centre of footing. Calculated displacements, rotations and bending moments were those that occurred from the bottom of the footing to the tip of the foundation.

It is found from the analysis that a circular $8.85 \mathrm{~m}$ diameter H-joint SPSP foundation shown in Table 4 has the same lateral bearing capacity with the circular $10.35 \mathrm{~m}$ diameter P-P joint SPSP foundation. The relationships between lateral load $(P)$ and normalized displacement $(\delta / D)$ of the circular $10.35 \mathrm{~m}$ diameter P-P joint SPSP foundation and that of the circular $8.85 \mathrm{~m}$ diameter H-joint SPSP foundation are plotted and compared in Fig. 19(a), where $\delta$ and $D$ is respectively the displacement of foundations and the diameter of the piles constituting the foundations. The lateral bearing capacity of the $10.35 \mathrm{~m}$ diameter P-P joint SPSP foundation and that of $8.85 \mathrm{~m}$ diameter $\mathrm{H}$-joint SPSP foundation at a normalized displacement of $1 \%$ are, respectively, 4.8 and 4.4 MN while at a normalized displacement of $10 \%$ is 


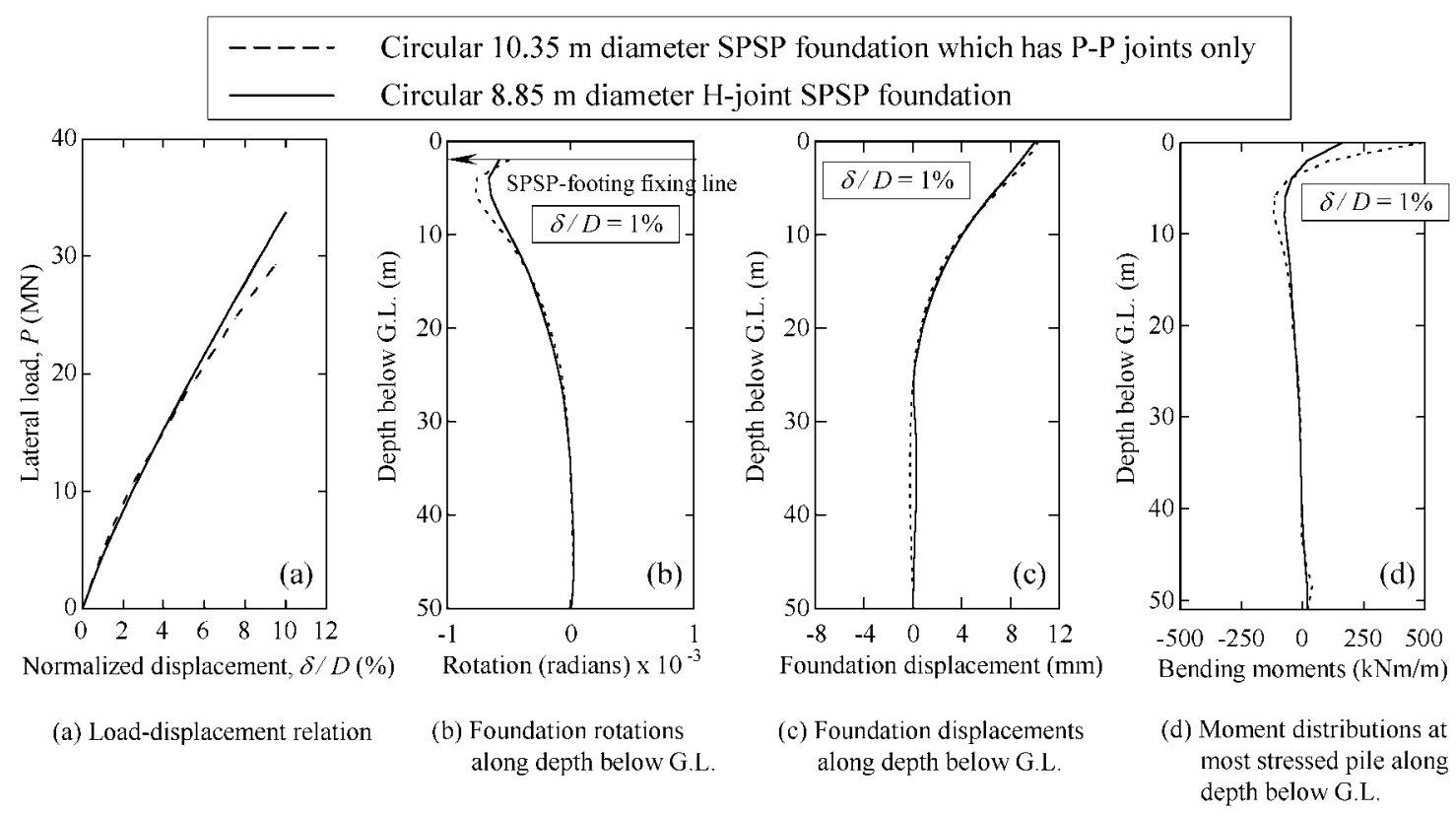

Fig. 19. Results showing that the cross sectional dimensions of SPSP foundations can be reduced when H-joint SPSP are used

30.3 and $33.7 \mathrm{MN}$. The capacities of the two foundations may be said to be equal despite differences in sizes. Weak nature of the P-P joint SPSP foundation may be attributed to relative shear movements at the P-P joints that occur when the structure is loaded, the H-joint SPSP foundation has high bearing capacity because it contains fewer P-P joints and more significantly is the fact that the $\mathrm{H}$-joint is rigidly welded continuously along the pile length and hence high flexural rigidity.

Rotations and displacements along the lengths of the foundations are checked to ensure that reduction in foundation size does not compromise other SPSP design requirements. Rotations that occurred after each pile underwent head displacement which corresponds to a normalized displacement of 1\% are shown in Fig. 19(b). The rotations may be said to be nearly equal; P-P joint SPSP foundation undergoes slightly more rotations near the ground surface and this is normal because effects of joint movements are more near the ground surface. Figure 19(c) shows that displacements along the foundations' lengths are approximately equal and the bending moments of the most stressed piles in the two foundations are compared at a normalized displacement of $1 \%$ in Fig. 19(d). The P-P joint SPSP foundation and the $\mathrm{H}$-joint SPSP had maximum bending moments of 494 and $166 \mathrm{kNm} / \mathrm{m}$ respectively. The piles in the P-P joint SPSP foundation experience clearly high bending moments compared to piles in the $8.85 \mathrm{~m}$ diameter $\mathrm{H}$-joint SPSP foundation despite its large size.

In conclusion, $\mathrm{H}$-joints afford reduction in SPSP foundation sizes, if need for a strong structure overrides need for structures with small sizes such as in coastal waste disposal landfills and retaining walls, the high strength of $\mathrm{H}$-joint SPSP enables smaller diameter pipe piles to be used. The analysis conducted in this section, and also the centrifuge experiments conducted in this research, do not consider the vertical bearing capacities of the two SPSP foundation types, therefore the contributions of $\mathrm{H}$-joints in reducing the SPSP foundation sizes will be evaluated later considering their vertical bearing capacities.

\section{Estimation of Joint Efficiency for Design of H-Joint SPSP}

Method (1) (beam analysis by finite length beam on an elastic foundation) is a simple design model widely used by SPSP designers. However, a joint efficiency $(\mu)$ is required to take into account the inevitable joint displacements. A $\mu=0.75$ is generally used in Eq. (1) during design of SPSP structures which have traditional joints (Japanese Association for Steel Pipe Piles, 1999). This background originates from a full-scale SPSP lateral loading test and an analysis by Method (1) for obtaining joint efficiency to be used in the design of SPSP foundations by Shima et al. (1970). As a result, they proposed that the value of 0.75 was to be used as a joint efficiency of SPSP foundations, in the case that the ground was assumed to be elasto-plastic body. However, since no known $\mu$ value for design of $\mathrm{H}$-joint SPSP exists, this parametric study was conducted to estimate it.

In this section, a practical $\mu$ for $\mathrm{H}$-joint SPSP and P-P joint SPSP foundations was estimated by carrying out parametric studies using the Method (2) (beam analysis by virtual open caisson beam considering shear displacement of the joints) and Method (1). Load-displacement $(P-\delta)$ relation obtained from Method (2) was defined as a basic curve in estimation of $\mu$ for each SPSP foundation. In addition, $P-\delta$ relation obtained from Method (1) by changing $\mu$ was made to coincide at a pile head displacement of $1 \%$ of the steel pipe diameter with the basiccurve (see Fig. 20). The $\mu$ for each SPSP foundation was that, value at which $P-\delta$ relations obtained by Methods 


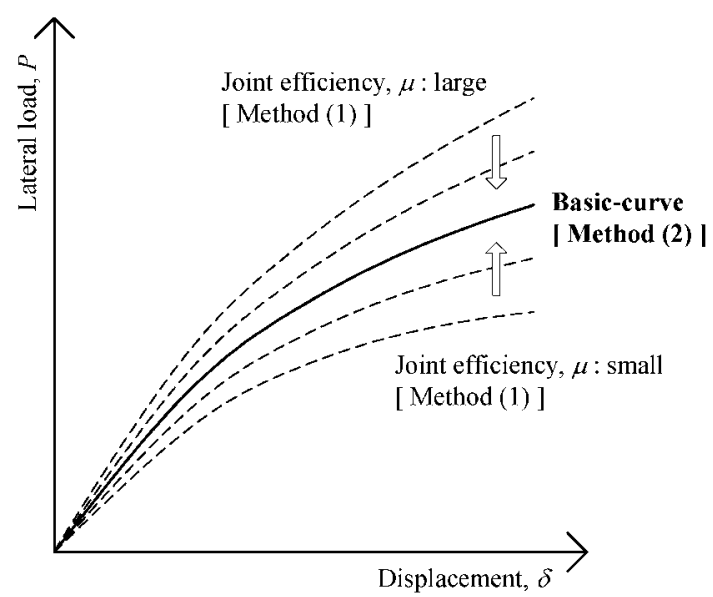

Fig. 20. Conceptual diagram of $P-\delta$ relations obtained from Methods (1) and (2)

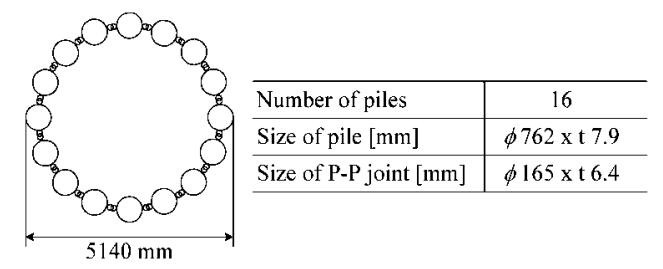

Fig. 21. Size of P-P joint SPSP foundation applied by Shima et al. (1979) and analysis

(1) and (2) coincide at the pile head displacement of $1 \%$ of the steel pipe diameter. In the estimation of $\mu$, the ground and traditional joint sections were assumed as elastic-plastic bodies while the footing position at the head of SPSP foundation was set to be a fixed condition.

In order to evaluate the validity of the calculation method of $\mu$, the $\mu$ of P-P joint SPSP foundation was calculated under the same conditions as those used by Shima et al. (1970) for the SPSP foundation and ground. The sizes of SPSP foundation and ground profile are shown in Figs. 21 and 22. Figure 23 shows experimental results and calculation result. By setting the $\mu$ at 0.75 in the analysis, the $P-\delta$ relation calculated from Method (1) agrees with that calculated from Method (2), and the experimental results by Shima et al. (1970), at the pile head displacement of $1 \%$ of the steel pipe diameter. Therefore, it is proven that this calculation method is appropriate.

Using this calculation method, each $\mu$ was calculated for P-P joint SPSP and H-joint SPSP foundations of various ground conditions and foundation sizes. The dimensions of P-P joint SPSP and H-joint SPSP analysis models are shown in Table 5. The foundation shapes considered were taken to be circular. Estimation of $\mu$ for each foundation was carried out under a constant penetration length of foundation of $32 \mathrm{~m}$. The assumed ground conditions penetrated by the SPSP foundation, both thickness and $N$-value of each composite layer were varied as shown in Fig. 24. The thickness of each composite layer was also varied so that their total thickness maintains the $32 \mathrm{~m}$ pile penetration depth. Under these

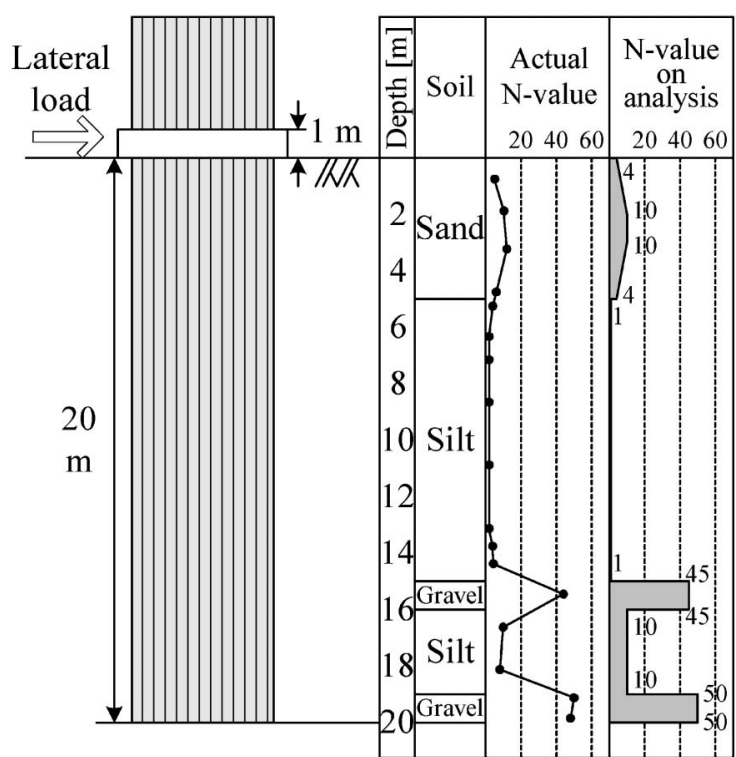

Fig. 22. Ground profile applied by Shima et al. (1979) and analysis

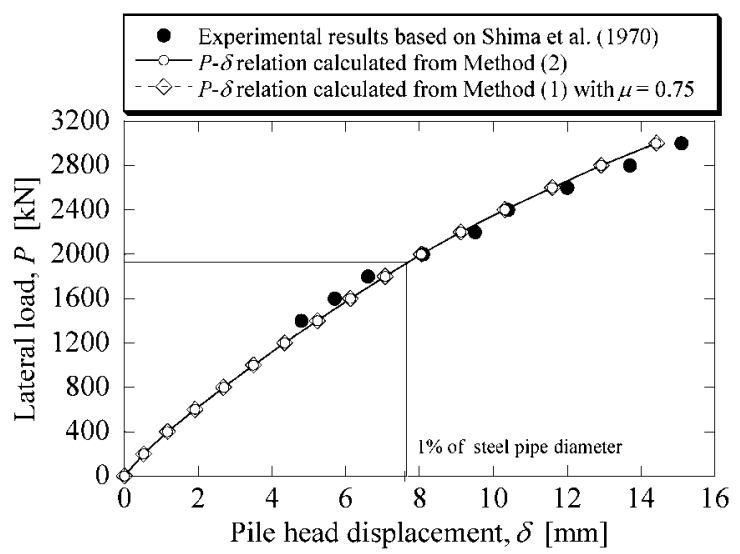

Fig. 23. Comparison between experimental result conducted by Shima et al. (1970) and calculation result

Table 5. Dimensions of P-P joint SPSP and $\mathbf{H}$-joint SPSP analysis models

\begin{tabular}{l|l} 
Number of pile & $8,12,16,20,24$ \\
Diameter of steel pipe [mm] & $600,800,1000$ \\
Thickness of steel pipe [mm] & $6,8,10,12,14$ \\
Diameter of P-P joint [mm] & 165 \\
Thickness of P-P joint [mm] & $6,8,10$ \\
Sizes of H-joint [mm] & $\mathrm{H} 400 \times 400 \times 13 \times 21$
\end{tabular}

assumed ground conditions, $\mu$ of P-P joint SPSP and $\mathrm{H}$-joint SPSP foundations was calculated using nonlinear analysis that treated the ground and joints as elastoplastic bodies. The ground constants, width of lateral load-resisting side of the SPSP foundations, and other calculation parameters were decided based on Public Works Research Institute (1977) and Japanese Association for Steel Pipe Piles (1999).

Figure 25 compares $\mu$ values for P-P joint SPSP and those of H-joint-SPSP, obtained under various ground conditions and SPSP foundation forms. The $\mu_{\mathrm{H}}$ of $\mathrm{H}$-joint SPSP foundation is larger than the $\mu_{\mathrm{P}-\mathrm{P}}$ of P-P 


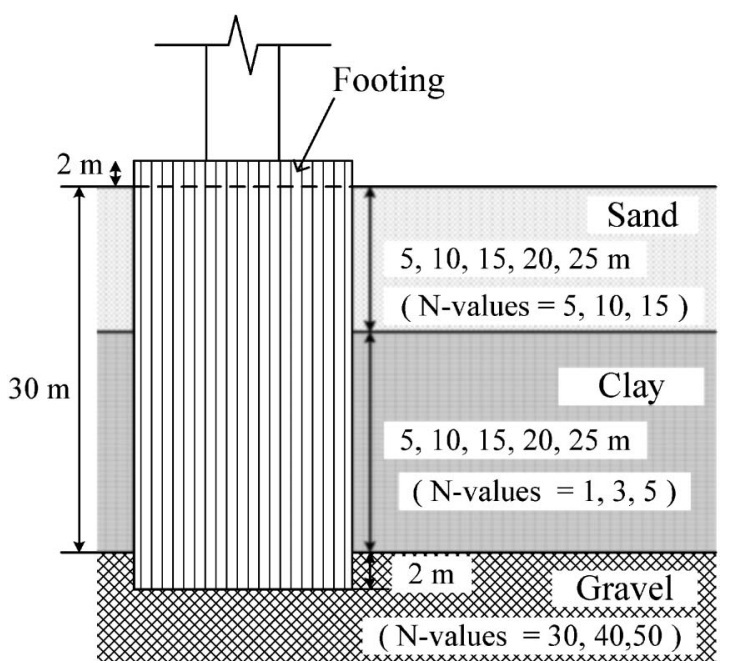

Fig. 24. Assumed ground conditions in which both thickness and $\mathrm{N}$-value of each composite layer is changed

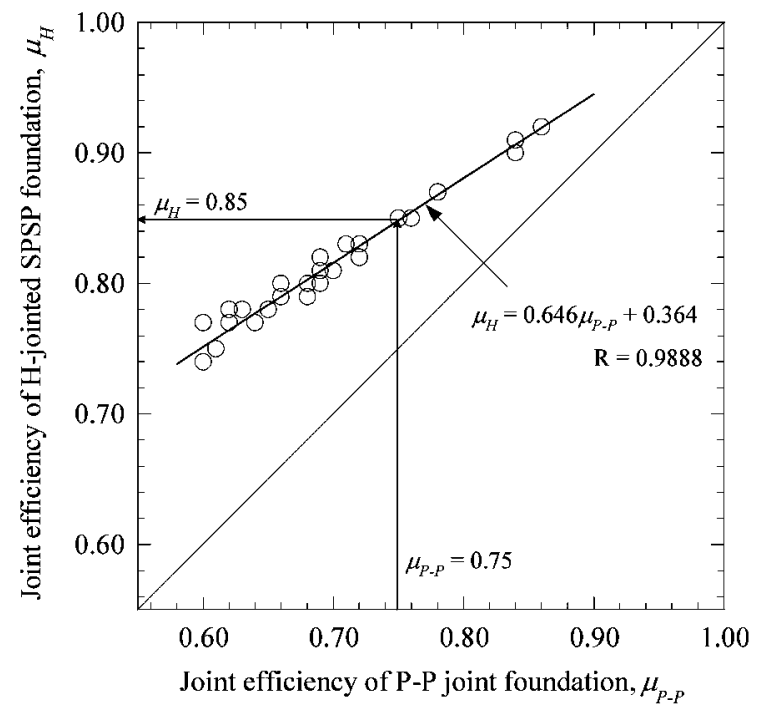

Fig. 25. Joint efficiency of the H-joint SPSP structures against those of P-P joint structures foundation

joint SPSP foundation. In addition, the relationship between $\mu_{\mathrm{P}-\mathrm{P}}$ and $\mu_{\mathrm{H}}$ obtained for various SPSP foundation forms under varied ground conditions can be represented by a linear relation, as shown in Fig. 24. When the analyzed relationship between $\mu_{\mathrm{H}}$ of $\mathrm{H}$-joint SPSP foundation and $\mu_{\text {P-P }}$ of P-P joint SPSP foundation is applied, for example, if the value $0.7,0.75$ or 0.8 was adopted as a joint efficiency for the P-P joint SPSP foundation, the corresponding joint efficiency proposed for designing the $\mathrm{H}$-joint SPSP foundation will be 0.82 , 0.85 or 0.88 respectively. This is because the application of $\mathrm{H}$-joint SPSPs can decrease the number of joint sections in the entire SPSP foundations compared with the application of SPSP with traditional joints. In addition, it originates the fact that the rigidity of $\mathrm{H}$-steel can be considered as a beam element in the design of H-joint SPSPs.

In design of SPSP foundations using the $\mathrm{H}$-joints, it is possible to set a higher joint efficiency than is the case with SPSP foundations using traditional joints. The rigidity of SPSP foundations decreases due to vertical shear movements at the traditional joint sections, therefore, this reduction in rigidity has been accounted for using a joint efficiency in Method (1). The fact that the joint efficiency of H-joint SPSP foundation is higher than that of P-P joint SPSP foundation means that the required number of piles for $\mathrm{H}$-joint SPSP foundation will be less because of their increased rigidity. The increased rigidity enables reduction in the dimensional size of designed SPSP foundation. It also contributes to a saving in labor costs besides the saving on construction time.

\section{CONCLUSIONS}

Broad objectives of this research were to develop the new $\mathrm{H}$-joint SPSP and explore how it can be used to improve performance of SPSP structures. The main conclusions are given below.

(1) Construction of $\mathrm{H}$-joint SPSP structures is practical and it can easily be constructed using the existing pile driving methods and that construction accuracy of H-joint SPSP is higher than that of ordinary piles. Because two piles are driven simultaneously, construction time is shortened and this means operation costs are reduced.

(2) An in-situ technique of connecting two H-joint SPSP segments using a fillet welded splice plate was proposed. The proposed field segment joint for $\mathrm{H}$-joint SPSP using a splice plate is strong and effective in bending strength requirements.

(3) The lateral bearing capacity of $\mathrm{H}$-joint SPSP foundation is larger than that of the SPSP foundation which has only P-P joints at the same normalized displacement of $10 \%$. Further, the $\mathrm{H}$-joint foundation is found to be 1.3 times stronger than the SPSP foundation which has only P-P joints at a normalized displacement of $10 \%$.

(4) H-joints afford reduction in SPSP foundation sizes, if need for a strong structure overrides need for structures with small sizes such as in coastal waste disposal landfills and retaining walls, the high strength of H-joint SPSP enables smaller diameter pipe piles to be used.

(5) A joint efficiency of $\mathrm{H}$-joint SPSP foundation is larger than that of P-P joint SPSP foundation. A value of 0.85 is proposed for use as a joint efficiency for the design of $\mathrm{H}$-joint SPSP foundation; this is true when a value of 0.75 is adopted as the joint efficiency for the design of P-P joint SPSP foundation.

In this research, the authors developed a new $\mathrm{H}$-joint SPSP from a simple idea in which two steel pipe piles are connected by $\mathrm{H}$-steel section welded on them. In order to improve the performance of the both outer sides in the $\mathrm{H}$-joint SPSP, the authors are introducing yet another joint referred to as the " $\mathrm{H}-\mathrm{H}$ joint", it is formed by 


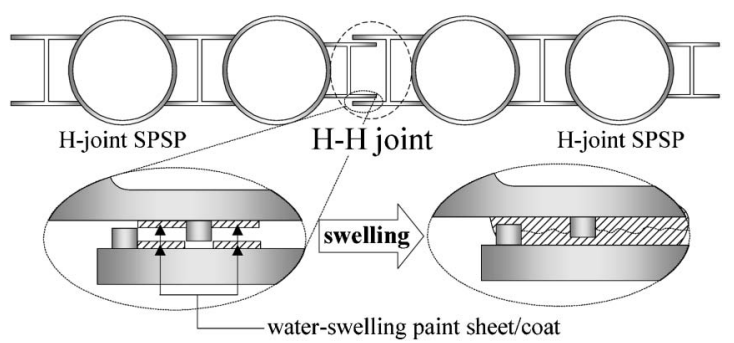

Fig. 26. Schematic diagram of proposed H-H joint

interlocking two H-steel sections of different sizes (see Fig. 26) (Inazumi et al., 2005). The $\mathrm{H}-\mathrm{H}$ joint will have a number of merits over the traditional joints which include high rigidity and low hydraulic conductivity in the joint part. The mechanical characteristics such as the compression, tension and shear property for the $\mathrm{H}-\mathrm{H}$ joint and its hydraulic performance will be verified.

\section{ACKNOWLEDGEMENT}

The authors would like to sincerely acknowledge the Nishimatsu Construction Co. Ltd. for affording us a chance to lent their Geotechnical Centrifuge Equipment, and also wish to express their sincere gratitude to each member of the Association for H-jointed Steel Pipe Sheet Piles Methods for their cooperation, their active and invigorating discussions, and useful information that they generously contributed to this study.

\section{REFERENCES}

1) Imamura, S., Hagiwara, T. and Nomoto, T. (1998): Nishimatsu dynamic geotechnical centrifuge, Proc. Int. Conf. Centrifuge 98, 25-30.

2) Inazumi, S., Kimura, M., Too, A. J. K. and Kamon, M. (2005): Performance of $\mathrm{H}$-jointed steel pipe sheet piles with $\mathrm{H}-\mathrm{H}$ joint in vertical hydraulic cutoff walls, Proc. 16th ICSMGE, 4, 2269-2272.

3) Japan Road Association (2002): Reference for Highway Bridge Design Specifications for Highway Bridges: Part IV; Substructures, Japan Road Association.

4) Japanese Association for Steel Pipe Piles (1999): Steel Pipe Sheet Pile Foundations-Design and Construction-, Japanese Association for Steel Pipe Piles (in Japanese).

5) Katayama, T., Nishimura, S. and Sakamoto, S. (1993): Recent developments in steel pipe sheet pile methods, Found. Mech., 11, 32-42 (in Japanese).

6) Kimura, M., Too, A. J. K., Isobe, K. and Nishiyama, Y. (2003): Offshore construction of bulkhead waste facilities by H-joint steel pipe sheet piles, Proc. Int. Conf. Found.; 'Innovations, Observations, Design and Practice', 443-452.

7) Kimura, M., Too, A. J. K., Inazumi, S., Isobe, K. and Nishiyama, Y. (2004): Innovative development of steel pipe sheet pile joint, Proc. 3rd Civil Engineering Conf. Asian Region, 373-377.

8) Public Works Research Institute (1977): Design of Sheet Pile Foundation, Public Works Research Institute, 1175(1) (in Japanese).

9) Shima, F., Kato, T. and Saito, J. (1970): Stiffness of steel pipe sheet pile foundations, Proc. 25th JSCE Annual Meeting, 41-44 (in Japanese).

10) Tomisawa, K. (2003): Verification of a vertical support system based on field management tests of long steel-pipe piles and sheet piles, Proc. 48th Nat. Symp. Geotech. Engrg., 141-148 (in Japanese).

11) Too, A. J. K., Kimura, M., Inazumi, S., Isobe, K. and Nishiyama, Y. (2004): Improvement of stability of steel pipe sheet pile structures using $\mathrm{H}$-joints, Proc. Int. Symp. Engineering Practices and Performance of Soil Deposits (IS-OSAKA 2004), 507-512. 